\title{
Measuring service quality in international fast food chains in Ludhiana
}

\begin{abstract}
The present study was undertaken to measure the service quality in International fast food chains in Ludhiana by selecting 200 customers on convenience basis. The primary data were collected with the help of a well structured schedule. An adopted SERVQUAL scale was used to assess the service quality. The study revealed that the service quality offered did not meet the customers' expectations on most aspects. The highest gap and poor internal consistency viz., 1.10 and 0.548 , respectively, was found in the parameter, empathy. The lowest gap and good internal consistency viz., 0.71 and 0.886 , respectively, was found in the parameter, reliability. The results further revealed that the reliability dimension was the most significant and tangibles dimension was the least significant amongst the five dimensions. Out of the five international fast food chains, the average scores for Pizza Hut were the highest on the three dimensions, namely, tangibles, reliability and empathy.
\end{abstract}

KEY WORDS : Service quality, International fast food chains, SERVQUAL

How to cite this paper : Verma Shivani (2015). Measuring service quality in international fast food chains in Ludhiana. Internat. J. Com. \& Bus. Manage, 8(1) : 51-57. 